pregnancy. In such cases, the ovum being lodged in an abnormal situation, ill adapted to supply sufficient nutriment for the embryo, it is not uncommonly found that the greater part or the entire surface of the chorion is developed into placenta. There is a well-marked example of this in Guy's Museum.

There is a form of placental growth by no means uncommon, which farther corroborates the view that any part of the chorion may be developed into placenta, according to the requirements of the embryo. There are the placenta spuria and the placenta succenturiata, to prove that true placental outgrowths may take place at a distance from the main placenta. Sometimes a placental mass of the size of a crown piece or larger is found wholly separate from the main placenta. This is not an unfrequent cause of secondary hæmorrhage after delivery. The placenta succenturiata remains adherent after the expulsion of the true placenta and the bulk of the membranes.

But there is yet another fact, of extreme importance in relation to this subject. I have been struck with the frequency with which prævial attachment is complicated with disease of the placenta and foetus. In examining and reflecting upon particular cases it has appeared to me that placental tufts may shoot out from one part of the chorion in preference to other parts, because some points, being diseased, are unfitted for efficient placentary development, or because some parts of the chorion, itself healthy, may be in contact with an unhealthy portion of decidua. Thus, if the fundal mucous membrane is diseased, there will be a tendency to placental development on that aspect of the ovum which is dirceted towards the lower segment of the uterus.

Another circumstance illustrating the frequent complication of disease with prævial placenta, is adhesion. It is important, however, not to confound the cases of true adhesion, in which there is organic change of structure, or abnormal deposit in the decidual portion of the placenta, with those more frequent cases in which the adhesion is merely the result of absent or ineffectual contraction of the uterus. We shall see by-and-bye that the muscular structure about the lower segment of the nterus is far less perfectly adapted to cast off the placenta than is the muscular structure of the fundus. This is one cause-a frequent one, and often unsuspected - of placental adhesion or retention. During my researches into the diseases of the placenta, many placentas have been brought to me, which having been retained, had been manually separated from the uterus on account of supposed morbid adhesions. It was rare to find in these specimens any trace of disease.

In a recent excellent paper, the present Dr. Legroux says, that placenta prævia mostly occurs in pluriparæ, and that it is due to the greater than normal enlargement of the uterus, which thus allows the orum to spread its attachments lower than is possible in the more inferiorly contracted, or pyriform, aterus of primiparæ.

One circumstance has struck almost every observer, and that is, the frequency with which the previal attachment of the placenta has occurred in the same patients. Some women are, therefore, especially prone to this complication. Is it rational to conclude that some women are especially prone to an "accidental" attachment of the placenta to the lower segment of the uterus ? No. It is not then an "accident;" but an occurrence depending upon definite and ascertainable causes.

I believe the etiological arguments thus enunciated are wellfounded. They do not exhaust the etiological historv. There are probably other causes. To eomplete the list is, I submit, an object eminently deserving of research. We should not rest contented with the quaint evasion of Portal, that these things happen, "selon qu'il plait à la nature de se jouer."

DIAGNOSIS OF PLACENTA PR.FVIA.

Are there any signs by which we may discenn the existence of placenta pravia b fore the occurrence of labour? This question is important, because, if we knew that this complication existed beforehand, we should be forearmed, and the better prepared to encounter the impending difficulty. Levret has examined the question with his usual acnmen. He enumerates the following signs of central or lateral placenta:-

1st. The belly of the patient is not pointed, or rounded as a ball, but somewhat flattened.

2ndly. It appears as if it were divided into two parts, as in the case of twin-pregnancy; but that which essentially distinguishes the first case from the second is, that the division is not found exactly in the middle, nor according to the vertical line of the body, but more on one side than the other, and a little obliquely. Moreover, if we question the woman, she will admit that in the first months of pregnancy she felt a swelling, with hardness, in one or the other side of her belly. 3rdly. This hardness had gone on increasing, and had never changed sides.

4thly. This side is the most painful spot of the whole belly, and that in which she fecls the movement of her child the least. These signs are perhaps wanting in precision, but their existence in any given cage should at least indicate more minute investigation.

Gendrin gives two signs. He says that a pulsation may be felt at the os uteri not synchronous with the mother's pulse; and, secondly, that owing to the interposition of the placenta ballottement cannot be performed. Neither of these signs is universally true.

It may be stated that the lower segment of the uterus is generally larger, softer, more fieshy than in ordinary gestation. The presenting part of the child either cannot be made out at all, or very indistinctly; and occasionally, when the os uteri will admit the finger, the quaggy place'ital mass may be felt. Sometimes a persistent dragging pain in it particular part has led to a stethoscopic examination, when the cervical attachment of the placenta has been accurately determined. This I have myself experienced.

Dr. Cohen, of Hamburg, has described the means of diagnosticating placenta prævia in a paper to which $I$ shall again have occasion to refer. His especial object is to determine which side of the lower segment of the uterus the main bulk of the placenta adheres to. He says the side of the uterus to which the main placenta grows is more swollen. In by far the greater number of cases this side is painful. The pain in the right epigastric region known to every acconcheur is a suffering so common in these circumstances that we regard the cases in which it does not appear there or on the other side as exceptional. Whenever this pain was strong, Cohen always found considerable fibrinous deposits in the placenta, and often stringy adhesions of the fœetal placenta to the uterus. The smaller part of the placenta, he says, is attached either to the right or left side; so seldom to the fore or after side, that for diagnosis it is enough to examine the right and left sides.

Moreau places little confidence in the condition of the os and cervix. He says: "One only phenomenon may cause a suspicion of the cervical insertion of the placenta: this is the epoch at which the hæmorrhages occur. Generally, they take place early in pregnancy, but they never arise before the moment when the neck of the organ begins to unfold itself. Most frequently, it is from the sixth to the seventh month."

The indications in diagnosis may be usefully summed up as follows:

1. The general signs, such as flattening of the abdomen, division of the abdominal tumour, and especially swelling and pain in one side of the pelvis pointed cut by Levret, should lead to minute exploration by the finger and stethoscope.

2. A bortions, disease of the placenta, dead children, and placenta prævia in former pregnancies, should also incite to minute physical exploration.

ON

\section{TUBERCLE OF THE CRUS CEREBELLT, WITH SYMPTOMS SIMULATING CHOREA.}

By T. H. SHUTE, M.D., PEYSICTAN TO THE TORBAT INFTRITART.

As any case tending to elucidate the physiology and patho. logy of the brain is of importance, I send the following, thinking it presents many points of interest to the readers of THr LANCET:-

Elizabeth S__, aged twenty-six, married three years, no family, was admitted under my care March 11 th, reported to be suffering from chorea. She presented the following appearance:--Countenance not sunken nor pallid, and not evidencing pain; fextures not distorted; muscular and adipose tissues sufficiently developed; tongue furred, rrotruded with a jerk; head constantly moving to the left side; articulation very imperfect; understands and answers everything that is said to her; constantly talking whilst awake; left arm in perpetual movement, being jerked across the chest, (during slcep the convulsive movements (ease, and she is quite tranquil;) total inability to support herself on her legs, but she can wove them up in the bed; sensation not affected; has a constant short cough, as if caused by accumulation of mucus; pulse 90 ; urine acid; no albuwen. There was mueh difficulty in examining 
the chest. Left side appeared duller than right; mucous and sub-crepitary rales, with respiratory sounds of the diffused blowing type, on that side.

The history of the case was very obscure. We could not ascertain that she had ever complained of headache; had had occasional cough for two years; had never spat blood. Four months since, whilst out walking, she suddenly fell against a wall, but without loss of conscionsness, since which time she has been in her present condition.

Diagnosis. - Organic disease at the base of the brain, probably softening, near the pons Varolii; tubercular disease of the left lung. She was ordered blisters to the calves of the legs; compound ipecacuanha powder, ten grains.

March 12th. - The Dover's powder had been repeated, and at the period of the visit she was in a profuse sweat, and in a quiet sleep; the movements of the arm had ceased.

13th. - Still quiet; takes her food when roused.

14th. - Very noisy; movements of arm and head lave recommenced. Ordered, acetate of morphia, potassio-tartrate of antimony, of each one grain; water, one ounce: one drachm to be taken every three hour's till she was quiet.

15th. - Only two doses of mixture had been taken, and she was in such a state of prostration as to require brandy and ammonia to ronse her.

16th. - Recovered from the state of prostration; movements of arm had ceased, and did not return; right pupil dilated, contracts under the influence of light, but dilates again immediately.

She died on the 6th of April.

A utopsy, forty-eight hours after death.-Vessels on convexity of brain congested; arachnoid membrane adherent along the upper and posterior edge of the longitudinal fissure; no evidences of recent inflammation of the membranes; consistence of brain firm, somewhat congested; no effusion into the ventricles; in slicing downwards, no appreciable lesion discoverable. At the base of the brain the right crus cerebelli was softened to the depth of a line on its anterior aspect, and in its substance were imbedded three crude tubercles the size of a pea, one in the centre, and two on each side, forming a triangle. The lungs were not taken from the thorax, but the posterior portion of the left was infiltrated with crude and softened tubercles.

Remarks.-The diagnosis in this case was somewhat obscure. On the one hand, we had all the symptoms of chorea, such as the constant agitation of the arm and head, the jerking protrusion of the tongue, difficulty of articulation, and perfect quietude during sleep. On the other hand, the age was not that at which chorea commences in the great majority of cases, and the mode and suddenness of the invasion of the malady was opposed to the idea of its being a purely nervous affection. Therefore we came to the conclusion that there was organic lesion, and that its seat was the base of the brain, which was verified by the autopsy. The deposition of tubercle in the brain of the adult is very rare, though common in children, "so much so that Louis only met with one case in 117 cases of phthisis; and Ingol, in his extensive practice at St. Louis, has only met with eight cases, and in six of these no symptom existed during life." * It will be remembered that in the experiments of Majendie, when he divided one of the crura cerebelli, the animal immediately began to rotate to the same side. Now here, although the patient in all probability fell sideways against a wall, the perpetual movement of the arm took place on the opposite to the diseased crus, the fibres of which were all but destroyed by disease; but the case is confirmatory of the proposition, "that individual parts of the brain answer individual purposes, as regards the power of regulating our movements.

July, 1857.

\section{THE ELECTRIC CAUTERY AND ITS APPLI- CATION TO DENTAL SURGERY.}

\section{By THOS. H. HARDING, EsQ.}

IT will be as well, at the commencement of the present communication, just to glance at the history of the introduction of the Filectrie oautery, and its general application in surgical practice. Crusell, of St. Petersburgh, was the first to employ it for surgical operations, although his researches generally, on its use, were not published before the year 1846 , yet his operations hear date anterior to those of any other surgeon.
In 1844, M. Louyet, of Brussels, recommended the operation for destroying the dental nerve ; and in 1845, Heider, of Vienna at the instigation of Steinheil, of Munich, cauterized the dental nerves with the galvanic cautery. In 1850, Mr. Marshall was the first to employ it in practical surgery in this country, but his researches were not published before 1851, when he brought the subject before the Royal Medical and Chirurgical Society in April of that year. In the same year I published a short paper on its use in dental surgery, being the first to adopt it in that special branch of surgery in this country; and in the same journal (THE LANCET), a paper also appeared from $\mathrm{Mr}$. Waite, recommending its use in dentistry.

Since 1851, it has been generally employed by others in England, France, and Germany.

Being deeply impressed with the great value of this powerfial agent in many of the most delicate operations which come under the hand of the general surgeon, from reading the papers com. municated to the Medico-Chirurgical Society by my friend, Mr. Marshall, giving in detail an account of the manner in which he employed the heat of electricity for the purpose of limited canterization in surgical disease, an abstract of which appeared in The LANCET, in May, 1851 ; and, again, a subsequent report of several operations performed by him, in which the results showed most satisfactorily the great value of this new agent, it struck me that its introduction into the practice of dental surgery would prove of inestimable value and of the greatest possible assistance, in effectually destroying the sensitive pulp of a decayed tooth, in a more certain, rapid, and safe manner than any of the numerous methods with which dentists are already familiar. I therefore conceived the idea, that a platinum wire, heated in the manner as recommended by Mr. Marshall, might be made available for the instantaneous destruction of an exposed tooth.pulp. I accordingly communicated my idea to Mr. Marshall, who fully concurred with me as to its importance. It had already suggested itself to his fertile mind, and had been mentioned by him as one of the obvious applications of his method of operating with the electric heat. His experience in this matter, moreover, enabled him to suggest for the purpose a very simple and suitable apparatus, which shall shortly be described.

In the first volume of THE LANCEr for 1851 there appeared a short communication from me on the destruction of the dental pulp by the heat of electricity, wherein I confidently stated that it might be regarded as a great advantage by all engaged in the practice of dental surgery. I had employed it for some months previous to the appearance of that paper, and fairly and justly claim to have been the first to use it in dental surgery in this country. In the same number of that journal was described an instrument for applying electric heat in dental operations, by $\mathrm{Mr}$. Waite; but I had used it before the time mentioned by Mr. Waite, and moreover was not acm quainted with his invention.

Now, other methods have been employed for applying heat to destroy the nerve of an aching tooth. The old village doctress has long been famous for curing toothache by the thrust of a hot needle or pin into the tootb, and dentists have occasionally used a heated wire. The actual cantery has long been a practice in vogue for the purpose of destroying the sensibility of the tooth-pulp from caries, and has been generally performed by heating a long piece of steel, small at one end, but terminating in a bulbous head about the size of a small pea, which is inserted into a handle. From the bulbous extremity urojects a piece of platina wire, smaller or larger according to circumstances; the bulbous end being heated in an ordinary lamp until a red or white heat is obtained, communicates the heat to the platinum wire, which is then immediately used for the purposes required. Another method of applying hot wires to the teeth is by means of platinum sponge and hydrogen gas, known as (Eropile; but I have had no experience of the use of this.

In regard to the use of the actual cautery, let us see what Mr. Snell says of it in his book on the teeth? he says, "Even now, it (the destruction by the actual cautery) is frequently performed in an improper manner, which will account for the want of success which often attends it when attempted by ignorant men. As the operation is very generally performed, it would be more properly styled carbonizing the cavity of the tooth generally, than simply cauterizing the membrane." It must be obvions to everyone that the great cause of failure, such as is here described, depends upon the difficulty experienced in obtaining a sufficient and permanent amount of heat; for it is well known that wire alone, which is the only substance sufinciently minute to be applied within the interior of a tooth, can retain the heat for but a very limited time. It 